\title{
Rapid diagnostic tests for imported malaria
}

\author{
Courtney A. Thompson MD, Andrea K. Boggild MD MSc
}

\section{Rapid diagnostic tests are immuno- chromatographic, instrument-free assays developed to detect malaria antigen quickly}

Rapid diagnostic tests are self-contained assays that use mono- or polyclonal antibodies to detect malaria antigens in blood by a colour change on a nitrocellulose strip. ${ }^{1}$ In nonendemic settings, these tests provide prompt laboratory diagnosis of malaria when expertise in microscopy is lacking. ${ }^{2}$ The results, whether positive or negative, must be confirmed by microscopy at a local reference centre. ${ }^{2}$ Polymerase chain reaction (PCR) may be used to confirm the presence of infection or identify the species when the microscopy results are equivocal, and it is available at some reference centres across Canada (Appendix 1, available at www.cmaj.ca/lookup/suppl/doi:10.1503 /cmaj.131794/-/DC1).

Test sensitivity is poor for nonfalciparum malaria

Rapid diagnostic tests have poor sensitivity for Plasmodium vivax (66\%-88\%) and give inferior performance at low levels of parasitemia $(0.01 \%$ or $\leq 500$ parasites $/ \mu \mathrm{L})$, which are common in patients with non-falciparum malaria. The tests lack sensitivity and specificity for other Plasmodium species in humans and should not be used to exclude non-falciparum malaria or to determine species or parasitemia. ${ }^{1}$

CMAJ invites submissions to "Five things to know about ..." Submit manuscripts online at http://mc.manuscriptcentral .com/cmaj

\section{Rapid diagnostic tests are designed to detect Plasmodium falciparum}

Rapid diagnostic tests are most useful for the prompt detection of malaria caused by P. falciparum, a species most likely to cause complications and death. Several rapid diagnostic tests are licensed in Canada and have different performance characteristics. $^{3}$ Most have high sensitivity ( $\geq 99 \%$ ) compared with PCR for $P$. falciparum when parasitemia levels are high ( $\geq 0.02 \%$ or $\geq 1000$ parasites $/ \mu \mathrm{L})$. Their sensitivity is lower $(\leq 75 \%)$ when parasitemia levels are $0.002 \%$ or less $(\leq 100$ parasites $/ \mu \mathrm{L}){ }^{1}$ Interpreting a negative result in children under age five and pregnant women requires caution, because they are more likely to have low levels of parasitemia and are at greatest risk for severe disease. ${ }^{4}$

\section{False-positive reactions can occur}

False-positive results of rapid diagnostic tests are rare but occur more commonly in nonendemic settings. Crossreactivity has been documented in patients with circulating autoantibodies such as antinuclear antibody and rheumatoid factor and in those with infections such as dengue fever, hepatitis $\mathrm{C}$, leishmaniasis, African trypanosomiasis, Chagas disease, schistosomiasis, tuberculosis and toxoplasmosis. ${ }^{1}$

\section{References}

1. Maltha J, Gillet P, Jacobs J. Malaria rapid diagnostic tests in travel medicine. Clin Microbiol Infect 2013;19:408-15.

2. Boggild A, Brophy J, Charlebois P, et al. Summary of recommendations for the diagnosis and treatment of malaria by the Committee to Advise on Tropical Medicine and Travel (CATMAT). Can Commun Dis Rep 2014;40:131-41.

3. Hawkes M, Kain KC. Advances in malaria diagnosis. Expert Rev Anti Infect Ther 2007;5:485-95.

4. Murray CK, Bennett JW. Rapid diagnosis of malaria. Interdiscip Perspect Infect Dis 2009;2009:415953.

5. Kyabayinze DJ, Tibenderana JK, Odong GW, et al. Operational accuracy and comparative persistent antigenicity of HRP2 rapid diagnostic tests for Plasmodium falciparum malaria in a hyperendemic region of Uganda. Malar J 2008;7:221.

Competing interests: Andrea Boggild has received speaker fees from the American Society for Microbiology and a grant from the Public Health Agency of Canada (PHAC); she is a mem-
Positive test results can occur following the completion of treatment

Rapid diagnostic tests that detect the antigen specific to $P$. falciparum can yield positive results for more than four weeks after treatment because of persistence of the sexual forms (gametocytes) of the parasite and slow clearance of the antigen. ${ }^{5}$ These tests should not be used for follow-up in patients with malaria. Microscopic examination of blood smears is required to detect parasites at the asexual stage, which cause disease.

ber of the Committee to Advise on Tropical Medicine and Travel and attends its annual meetings through travel support from PHAC. No competing interests were declared by Courtney Thompson.

This article has been peer reviewed.

Affiliations: Department of Medicine (Thompson, Boggild), University of Toronto; Laboratory Services (Boggild), Public Health Ontario; Tropical Disease Unit (Boggild), Division of Infectious Diseases, University Health Network, Toronto General Hospital, Toronto, Ont.

Correspondence to: Andrea K. Boggild, andrea.boggild@utoronto.ca

CMAJ 2014. DOI:10.1503/cmaj.131794 